\title{
Heat capacity, thermal expansion, and thermal diffusivity of $\mathrm{NaUO}_{2} \mathrm{BO}_{3}$
}

\author{
Karin Popa ${ }^{1}(1) \cdot$ Ondrej Beneš $^{1} \cdot$ Dragoş Staicu $^{1} \cdot$ Jean-Christophe Griveau ${ }^{1} \cdot$ Eric Colineau $^{1} \cdot$ Alice Seibert $^{1}$ • \\ Jean-Yves Colle ${ }^{1} \cdot$ Sarah Stohr $^{1} \cdot$ Philippe E. Raison $^{1} \cdot$ Joseph Somers $^{1} \cdot$ Rudy J. M. Konings $^{1}$
}

Received: 21 July 2017 / Accepted: 11 December 2017 / Published online: 20 December 2017

(C) The Author(s) 2017. This article is an open access publication

\begin{abstract}
In the present studies, the thermal behaviour of $\mathrm{NaUO}_{2} \mathrm{BO}_{3}$ has been investigated. This compound is a potential product of interaction between the coolant $(\mathrm{Na})$, control rods $\left(\mathrm{B}_{4} \mathrm{C}\right)$, and the oxide fuel, which could form under accidental conditions in sodium-cooled fast reactors. The thermal expansion, the heat capacity, and thermal diffusivity of $\mathrm{NaUO}_{2} \mathrm{BO}_{3}$ have been measured. The thermal conductivity of the material is derived from these results and presented here for the first time.
\end{abstract}

Keywords Sodium uranyl borate $\cdot$ Solid state reactions · Thermal expansion · Thermodynamic properties .

Calorimetry $\cdot$ Thermal analysis

\section{Introduction}

Sodium uranyl borate $\mathrm{NaUO}_{2} \mathrm{BO}_{3}$ (or $\mathrm{NaUBO}_{5}$ ) is the only anhydrous borate that forms in the $\mathrm{Na}-\mathrm{U}-\mathrm{B}-\mathrm{O}$ phase diagram [1-3]. This compound has been reported for the first time by Hoekstra [4], and its crystal structure was determined by Gasparin [5] from X-ray diffraction data measurements on single crystal. $\mathrm{NaUO}_{2} \mathrm{BO}_{3}$ crystallises in an orthorhombic unit cell in the space group Pcam $\left(\mathrm{N}^{\circ} 57\right)$. In this structure, uranium atoms are sevenfold coordinated, the boron atoms have three coplanar surrounding oxygen and sodium atoms are sixfold coordinated and linked together by three oxygen atoms along the $c$ axis as shown in Fig. 1.

An extensive thermodynamic characterisation has been performed by Chernurukov et al. [6, 7]. The latter authors measured the enthalpy of formation and the low-temperature heat capacity, from which the Gibbs energy was derived as $\Delta_{\mathrm{f}} G^{\circ}(298.15 \mathrm{~K})=-(2122.5 \pm 5.0) \mathrm{kJ} \mathrm{mol}^{-1}$. This results in a reaction energy from the oxides of

Electronic supplementary material The online version of this article (https://doi.org/10.1007/s10973-017-6923-y) contains supplementary material, which is available to authorized users.

Karin Popa

karin.popa@ec.europa.eu

1 European Commission, Joint Research Centre, P.O. Box 2340, 76125 Karlsruhe, Germany
$\Delta_{\mathrm{r}} G^{\circ}(298.15 \mathrm{~K})=-(190.5 \pm 5.1) \mathrm{kJ} \mathrm{mol}^{-1}$, indicating that the compound can form under oxidising conditions when the oxides of sodium, uranium, and boron are mixed together. This could occur for instance in nuclear borosilicate waste glasses (containing about $10 \mathrm{wt} \%$ sodium oxide) or in the debris of damaged nuclear reactor cores containing oxidised fuel and $\mathrm{B}_{4} \mathrm{C}$ control rod material, such as in Fukushima case (reaction with the sodium ions from the cooling sea water).

In the present study, we have extended the thermodynamic characterisation of this compound to higher temperatures and determined the thermal expansion, the enthalpy increment, and the thermal diffusivity, from which the heat capacity and thermal conductivity are derived. In addition, we re-measured the low-temperature heat capacity in order to verify the change in the slope observed by Karyakin et al. [6] in their measurements.

\section{Materials and methods}

\section{Synthesis and material processing}

$\mathrm{NaUO}_{2} \mathrm{BO}_{3}$ was produced using a simplified solid state reaction procedure. Thus, stoichiometric amounts of commercial $\mathrm{NaHCO}_{3}$ (Alfa Aesar, 99.7\%), $\mathrm{H}_{3} \mathrm{BO}_{3}$ (SigmaAldrich, $99.999 \%$ ), and $\mathrm{UO}_{2.10}$ (COGEMA powder, stoichiometry calculated from the value of the lattice 
Fig. 1 Sketch of the crystal structure of $\mathrm{NaUO}_{2} \mathrm{BO}_{3}$ (atomic positions from Gasperin [5])

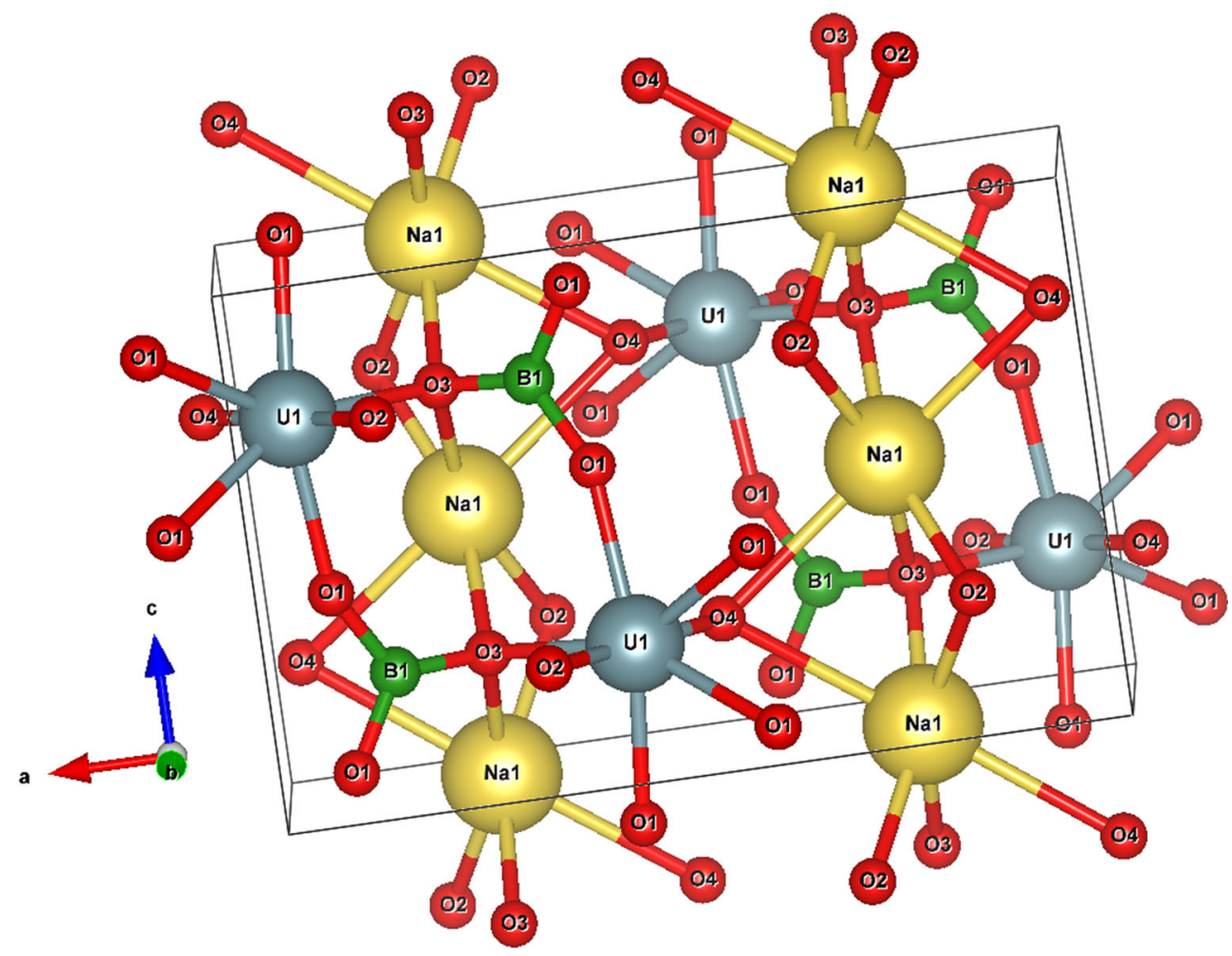

parameter) were reacted for $5 \mathrm{~h}$ at $1173 \mathrm{~K}$ under an air atmosphere. Pellets of $3.5 \mathrm{~mm}$ diameter and $1-2 \mathrm{~mm}$ in height were produced by pressing and re-heated at $1173 \mathrm{~K}$ under air for another $5 \mathrm{~h}$.

\section{XRD analysis}

$\mathrm{NaUO}_{2} \mathrm{BO}_{3}$ was characterised at room temperature by X-ray powder diffraction (XRD) using a Bruker D8 diffractometer mounted in a Bragg-Brentano configuration with a curved $\mathrm{Ge}(1,1,1)$ monochromator, a ceramic copper tube $(40 \mathrm{kV}, 40 \mathrm{~mA})$ and equipped with a LynxEye position sensitive detector. The data were collected by step scanning in the angle range $10^{\circ} \leq 2 \theta \leq 120^{\circ}$ at a $2 \theta$ step size of $0.0092^{\circ}$. For the measurements, the powder was deposited on a silicon wafer to minimise the background and dispersed on the surface with several drops of isopropanol. The structural refinement was performed using the Fullprof2k suite [8]. The shape of the peaks was described by a Pseudo-Voigt function, and the background was fitted by a linear interpolation between a set of about 50 background points.

The thermal expansion of $\mathrm{NaUO}_{2} \mathrm{BO}_{3}$ was measured by high-temperature X-ray diffraction. The data were collected on a second Bruker D8 X-ray diffractometer mounted with a curved Ge $(1,1,1)$ monochromator, a copper ceramic X-ray tube $(40 \mathrm{kV}, 40 \mathrm{~mA})$, a LynxEye position sensitive detector and equipped with an Anton
Paar HTK 2000 chamber. Measurements were conducted up to $1073 \mathrm{~K}$ under helium, in the angle range $16^{\circ} \leq 2 \theta \leq 90^{\circ}$ with a $2 \theta$ step size of $0.017^{\circ}$.

\section{Raman and IR spectroscopy}

$\mathrm{NaUO}_{2} \mathrm{BO}_{3}$ was characterised in the temperature range from 6 to $290 \mathrm{~K}$ by Raman spectroscopy using a JobinYvon $^{\circledR}$ T 64000 equipped with a macro-inlet. To obtain the Raman spectra, a laser excitation source was used to illuminate the pressed powder sample fixed with indium inside the cold finger of a closed cycle He cryostat. The scattered radiation from the surface was detected with a low-noise $\mathrm{LN}_{2}$-cooled CCD detector after separation of the Raman signal from the Rayleigh component. The excitation source was a $\mathrm{Kr}^{+}$Coherent $^{\circledR} \mathrm{cw}$ laser radiating at $647 \mathrm{~nm}$ with a power of $50 \mathrm{~mW}$. Spectra were obtained with an acquisition time of $10 \mathrm{~s}$.

FT-IR spectra were measured using Bruker Alpha spectrometer employing the attenuated total reflectance (ATR) technique with a resolution of $0.01 \mathrm{~cm}^{-1}$ in a range $375-4000 \mathrm{~cm}^{-1}$. No special preparation for powder samples was necessary for this technique.

\section{DTA/TG measurements}

The thermal behaviour was investigated using a Netzsch STA 449C DTA/TG, using an alumina crucible and 
different atmospheres (Ar and air). The temperature was controlled by a Pt-PtRh (10\%) thermocouple. The applied heating and cooling rates were $10 \mathrm{~K} \mathrm{~min}^{-1}$.

\section{Heat capacity measurements}

The low-temperature heat capacity of $\mathrm{NaUO}_{2} \mathrm{BO}_{3}$ was measured on a pellet of $51.9 \mathrm{mg}$ from 293.4 to $1.82 \mathrm{~K}$ at $0 \mathrm{~T}$ with a PPMS-9T instrument (quantum design) using the hybrid adiabatic relaxation method, in the absence and the presence of the magnetic field. The sample was fixed on the sapphire platform by a small amount of thermal conductive grease (Apiezon-N). The heat capacity contributions of the puck and of the layer of grease were determined separately through the addenda protocol determination. A complete description of the technique and the method has been reported by Lashley et al. [9], whereas details of the instrument used in this work can be found in Javorský et al. [10]. Based on comparison with standard materials and experience for other compounds, we estimate the uncertainty of the measurements to be better than $3 \%$, depending on the temperature range.

Solid pieces of 53.7-62.9 mg were further used to measure the enthalpy increments using a Setaram multidetector high-temperature calorimeter (MDHTC-96) using a drop detector. For more details about the technique, we refer to our previous studies $[11,12]$. The measurements were carried out under an argon atmosphere. The temperature range of the experiment was from 482.5 to $1190.5 \mathrm{~K}$. Each isothermal run consisted of three drops of analysed material. Before and after each sample, a reference material (platinum ingots of 99.95 at.\% purity) was dropped to determine the sensitivity (signal vs. heat ratio) of the detector. The drops were separated by time intervals of $20 \mathrm{~min}$, long enough to re-stabilise the monitored heat flow signal. All evaluations of the background subtraction and peak integration were done using commercially available software for data processing. The reported temperatures were corrected (ITS-90) in accordance with the calibration curve obtained prior to measurement using several highpurity standard metals ( $\mathrm{Sn}, \mathrm{Pb}, \mathrm{Zn}, \mathrm{Al}, \mathrm{Ag}, \mathrm{Ni}$ ) with various melting temperatures in order to cover the whole temperature range of the measurement.

\section{Thermal diffusivity measurements}

The thermal diffusivity measurements were carried out using a laser flash device, designed and constructed in house [13]. The curves were measured with pyrometers. The samples were heated at the measurement temperatures in a high-frequency furnace, in the temperature range from 500 to about $1130 \mathrm{~K}$. The samples were disc fragments with a thickness of about $1 \mathrm{~mm}$. The faces were checked to ensure that they were plane and parallel, without defects.

\section{Results and discussions}

\section{Structural characterisation and thermal expansion}

The synthesis resulted in pure phase $\mathrm{NaUO}_{2} \mathrm{BO}_{3}$ (space group $P$ cam, $Z=4$ ), as confirmed by room temperature XRD and vibrational spectroscopy. The results of our refinement are in good agreement with the previous literature reports. Table 1 summarises the main experimental crystallographic data of the present studies.

The DTA/TG and measurements performed under air and argon indicated that $\mathrm{NaUO}_{2} \mathrm{BO}_{3}$ is stable up to $1470 \mathrm{~K}$ (supplementary material S1). However, a slight change in colour may be observed at about $1200 \mathrm{~K}$, indicating that a transformation is occurring already at this temperature. Moreover, the HTXRD measurements performed under inert atmosphere indicated the appearance of $\mathrm{U}_{3} \mathrm{O}_{8}$ as a secondary phase at $1273 \mathrm{~K}$. This is the reason of limiting our heat capacity and thermal expansion measurement around $1200 \mathrm{~K}$.

The relative variation of the cell parameters of $\mathrm{NaUO}_{2} \mathrm{BO}_{3}$ with temperature is presented in Fig. 2. The

Table 1 Unit cell parameters of $\mathrm{NaUO}_{2} \mathrm{BO}_{3}$

\begin{tabular}{lllll}
\hline & $a / \AA$ & $b / \AA$ & $c / \AA$ & $V / \AA^{3}$ \\
\hline Present work & $10.725(2)$ & $5.784(2)$ & $6.863(2)$ & 425.74 \\
Gasperin [5] & $10.712(3)$ & $5.780(1)$ & $6.862(2)$ & 424.86 \\
Karyakin et al. [6] & $10.705(2)$ & $5.788(1)$ & $6.862(2)$ & 424.17 \\
\hline
\end{tabular}

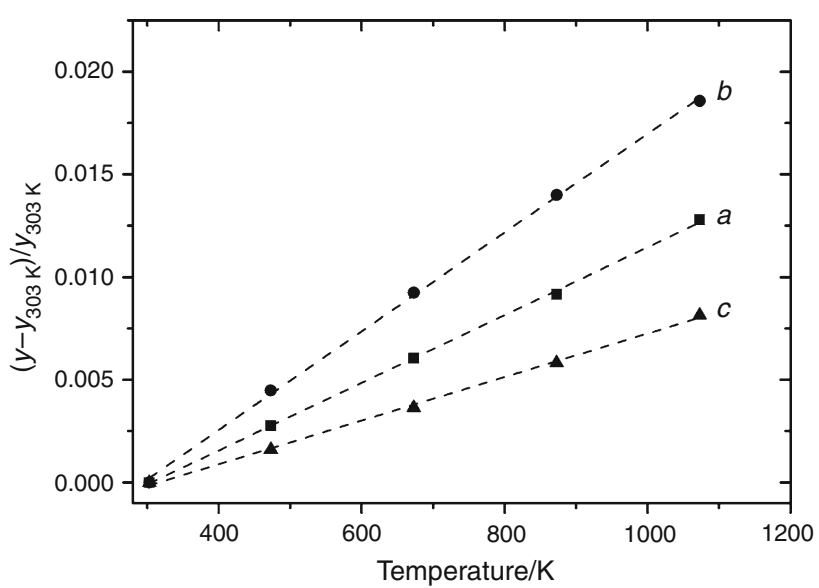

Fig. 2 Relative variation of the cell parameters of $\mathrm{NaUO}_{2} \mathrm{BO}_{3}$ with temperature 
Table 2 Experimental low-temperature heat capacity data for $\mathrm{NaUO}_{2} \mathrm{BO}_{3}$ in the absence of the magnetic field

\begin{tabular}{|c|c|c|c|c|c|c|c|}
\hline$T / \mathrm{K}$ & $C_{\mathrm{p}} / \mathrm{J} \mathrm{K}^{-1} \mathrm{~mol}^{-1}$ & $T / \mathrm{K}$ & $C_{\mathrm{p}} / \mathrm{J} \mathrm{K}^{-1} \mathrm{~mol}^{-1}$ & $T / \mathrm{K}$ & $C_{\mathrm{p}} / \mathrm{J} \mathrm{K}{ }^{-1} \mathrm{~mol}^{-1}$ & $T / \mathrm{K}$ & $C_{\mathrm{p}} / \mathrm{J} \mathrm{K}^{-1} \mathrm{~mol}^{-1}$ \\
\hline 293.40 & 142.83 & 186.75 & 115.77 & 71.886 & 52.331 & 26.788 & 11.935 \\
\hline 293.42 & 142.80 & 184.81 & 115.38 & 69.908 & 50.642 & 26.404 & 11.616 \\
\hline 293.42 & 142.79 & 182.80 & 115.01 & 67.933 & 48.920 & 26.000 & 11.282 \\
\hline 291.00 & 142.33 & 180.89 & 114.51 & 65.957 & 47.190 & 25.641 & 10.952 \\
\hline 291.41 & 142.43 & 178.87 & 114.11 & 63.982 & 45.423 & 25.224 & 10.596 \\
\hline 291.41 & 142.45 & 176.90 & 113.68 & 62.006 & 43.660 & 24.775 & 10.244 \\
\hline 289.45 & 142.19 & 174.96 & 113.27 & 60.030 & 41.883 & 24.443 & 9.9551 \\
\hline 287.07 & 141.60 & 172.95 & 112.77 & 58.057 & 40.116 & 23.976 & 9.5584 \\
\hline 285.15 & 140.98 & 170.97 & 112.12 & 56.083 & 38.323 & 23.626 & 9.2884 \\
\hline 283.19 & 140.40 & 168.99 & 111.49 & 54.111 & 36.511 & 23.162 & 8.9033 \\
\hline 281.25 & 139.65 & 167.03 & 110.82 & 52.136 & 34.694 & 22.790 & 8.6148 \\
\hline 279.29 & 138.94 & 165.04 & 110.06 & 50.160 & 32.867 & 22.375 & 8.2808 \\
\hline 277.33 & 138.26 & 163.06 & 109.26 & 48.190 & 31.018 & 21.987 & 7.9789 \\
\hline 275.38 & 137.72 & 161.09 & 108.46 & 46.196 & 29.166 & 21.574 & 7.6633 \\
\hline 273.41 & 137.28 & 159.11 & 107.63 & 44.230 & 27.350 & 21.178 & 7.3681 \\
\hline 271.46 & 136.94 & 157.13 & 106.72 & 44.403 & 27.549 & 20.781 & 7.0732 \\
\hline 269.50 & 136.57 & 155.15 & 105.86 & 43.798 & 26.947 & 20.372 & 6.7791 \\
\hline 267.54 & 136.17 & 153.17 & 104.91 & 43.395 & 26.596 & 19.983 & 6.5022 \\
\hline 265.58 & 135.68 & 151.19 & 104.00 & 42.992 & 26.223 & 19.575 & 6.2072 \\
\hline 263.62 & 135.25 & 149.21 & 103.02 & 42.590 & 25.860 & 19.192 & 5.9356 \\
\hline 261.66 & 134.78 & 147.23 & 102.15 & 42.188 & 25.490 & 18.776 & 5.6487 \\
\hline 259.70 & 134.30 & 145.25 & 101.19 & 41.784 & 25.122 & 18.405 & 5.3954 \\
\hline 257.74 & 133.88 & 143.28 & 100.18 & 41.380 & 24.758 & 17.972 & 5.1091 \\
\hline 255.78 & 133.46 & 141.30 & 99.136 & 40.976 & 24.388 & 17.621 & 4.8814 \\
\hline 253.82 & 133.01 & 139.32 & 98.089 & 40.573 & 24.029 & 17.171 & 4.5883 \\
\hline 251.85 & 132.59 & 137.33 & 97.004 & 40.052 & 23.583 & 16.831 & 4.3725 \\
\hline 249.88 & 132.13 & 135.35 & 95.964 & 39.631 & 23.210 & 16.378 & 4.0918 \\
\hline 247.93 & 131.64 & 133.37 & 94.897 & 39.245 & 22.853 & 16.031 & 3.8800 \\
\hline 245.96 & 131.23 & 131.38 & 93.836 & 38.839 & 22.498 & 15.596 & 3.6215 \\
\hline 243.99 & 130.69 & 129.40 & 92.722 & 38.431 & 22.144 & 15.229 & 3.4080 \\
\hline 242.03 & 130.24 & 127.42 & 91.599 & 38.026 & 21.794 & 14.813 & 3.1730 \\
\hline 240.06 & 129.71 & 125.43 & 90.471 & 37.625 & 21.433 & 14.436 & 2.9632 \\
\hline 238.09 & 129.17 & 123.45 & 89.359 & 37.238 & 21.089 & 14.456 & 2.9747 \\
\hline 236.12 & 128.62 & 121.47 & 88.171 & 36.841 & 20.741 & 14.229 & 2.8515 \\
\hline 234.14 & 128.08 & 119.48 & 86.982 & 36.446 & 20.391 & 14.026 & 2.7437 \\
\hline 232.17 & 127.51 & 117.50 & 85.808 & 36.044 & 20.039 & 13.828 & 2.6424 \\
\hline 230.20 & 126.98 & 115.51 & 84.615 & 35.642 & 19.695 & 13.636 & 2.5445 \\
\hline 228.22 & 126.55 & 113.53 & 83.355 & 35.245 & 19.351 & 13.447 & 2.4510 \\
\hline 226.25 & 126.07 & 111.54 & 82.181 & 34.850 & 19.009 & 13.258 & 2.3567 \\
\hline 224.29 & 125.61 & 109.56 & 80.910 & 34.447 & 18.684 & 13.065 & 2.2628 \\
\hline 222.32 & 125.07 & 107.57 & 79.606 & 34.038 & 18.373 & 12.880 & 2.1739 \\
\hline 220.35 & 124.55 & 105.58 & 78.306 & 33.636 & 18.024 & 12.698 & 2.0887 \\
\hline 218.38 & 123.97 & 103.59 & 76.946 & 33.232 & 17.662 & 12.517 & 2.0065 \\
\hline 216.40 & 123.39 & 101.61 & 75.588 & 32.836 & 17.287 & 12.342 & 1.9290 \\
\hline 214.43 & 122.83 & 99.627 & 74.154 & 32.442 & 16.917 & 12.170 & 1.8539 \\
\hline 212.45 & 122.30 & 97.644 & 72.711 & 32.037 & 16.545 & 12.001 & 1.7817 \\
\hline 210.48 & 121.81 & 95.667 & 71.269 & 31.620 & 16.168 & 11.834 & 1.7104 \\
\hline 208.51 & 121.37 & 93.684 & 69.784 & 31.192 & 15.795 & 11.668 & 1.6423 \\
\hline
\end{tabular}


Table 2 (continued)

\begin{tabular}{|c|c|c|c|c|c|c|c|}
\hline$T / \mathrm{K}$ & $C_{\mathrm{p}} / \mathrm{J} \mathrm{K}{ }^{-1} \mathrm{~mol}^{-1}$ & $T / \mathrm{K}$ & $C_{\mathrm{p}} / \mathrm{J} \mathrm{K}{ }^{-1} \mathrm{~mol}^{-1}$ & $T / \mathrm{K}$ & $C_{\mathrm{p}} / \mathrm{J} \mathrm{K}{ }^{-1} \mathrm{~mol}^{-1}$ & $T / \mathrm{K}$ & $C_{\mathrm{p}} / \mathrm{J} \mathrm{K} \mathrm{K}^{-1} \mathrm{~mol}^{-1}$ \\
\hline 206.53 & 120.83 & 91.700 & 68.308 & 30.781 & 15.441 & 11.504 & 1.5755 \\
\hline 204.55 & 120.28 & 89.713 & 66.763 & 30.380 & 15.101 & 11.344 & 1.5116 \\
\hline 202.60 & 119.78 & 87.735 & 65.225 & 29.975 & 14.777 & 11.177 & 1.4469 \\
\hline 200.60 & 119.20 & 85.764 & 63.641 & 29.575 & 14.426 & 11.019 & 1.3876 \\
\hline 198.62 & 118.72 & 83.783 & 62.035 & 29.179 & 14.080 & 10.863 & 1.3291 \\
\hline 196.68 & 118.20 & 81.801 & 60.415 & 28.799 & 13.734 & 10.710 & 1.2734 \\
\hline 194.67 & 117.67 & 79.832 & 58.791 & 28.387 & 13.293 & 10.560 & 1.2201 \\
\hline 192.69 & 117.18 & 77.837 & 57.294 & 28.024 & 13.033 & 10.414 & 1.1691 \\
\hline 190.71 & 116.69 & 75.846 & 55.607 & 27.564 & 12.610 & 10.271 & 1.1214 \\
\hline 188.73 & 116.26 & 73.866 & 53.991 & 27.207 & 12.290 & 10.126 & 1.0735 \\
\hline 9.985 & 1.0292 & 6.727 & 0.29107 & 4.483 & 0.08256 & 3.040 & 0.02563 \\
\hline 9.846 & 0.98623 & 6.614 & 0.27586 & 4.420 & 0.07926 & 3.000 & 0.02463 \\
\hline 9.707 & 0.94372 & 6.471 & 0.25766 & 4.359 & 0.07599 & 2.960 & 0.02366 \\
\hline 9.572 & 0.90350 & 6.374 & 0.24607 & 4.299 & 0.07286 & 2.919 & 0.02273 \\
\hline 9.438 & 0.86478 & 6.285 & 0.23471 & 4.239 & 0.06985 & 2.881 & 0.02191 \\
\hline 9.307 & 0.82720 & 6.196 & 0.22433 & 4.181 & 0.06687 & 2.841 & 0.02116 \\
\hline 9.176 & 0.79137 & 6.111 & 0.21453 & 4.122 & 0.06410 & 2.804 & 0.02043 \\
\hline 9.047 & 0.75719 & 6.025 & 0.20500 & 4.059 & 0.06086 & 2.765 & 0.01995 \\
\hline 8.920 & 0.72341 & 5.941 & 0.19625 & 4.002 & 0.05847 & 2.701 & 0.01854 \\
\hline 8.796 & 0.69209 & 5.857 & 0.18742 & 3.946 & 0.05607 & 2.645 & 0.01758 \\
\hline 8.672 & 0.66133 & 5.775 & 0.17940 & 3.892 & 0.05376 & 2.589 & 0.01665 \\
\hline 8.549 & 0.63162 & 5.695 & 0.17168 & 3.838 & 0.05146 & 2.532 & 0.01577 \\
\hline 8.424 & 0.60224 & 5.615 & 0.16432 & 3.785 & 0.04930 & 2.478 & 0.01498 \\
\hline 8.305 & 0.57545 & 5.535 & 0.15731 & 3.734 & 0.04733 & 2.425 & 0.01421 \\
\hline 8.188 & 0.54973 & 5.458 & 0.15063 & 3.682 & 0.04541 & 2.365 & 0.01331 \\
\hline 8.074 & 0.52584 & 5.382 & 0.14456 & 3.631 & 0.04359 & 2.314 & 0.01261 \\
\hline 7.961 & 0.50263 & 5.306 & 0.13821 & 3.582 & 0.04184 & 2.266 & 0.01193 \\
\hline 7.849 & 0.48066 & 5.232 & 0.13240 & 3.533 & 0.04027 & 2.217 & 0.01123 \\
\hline 7.740 & 0.45896 & 5.158 & 0.12650 & 3.485 & 0.03864 & 2.168 & 0.01056 \\
\hline 7.632 & 0.43879 & 5.088 & 0.12118 & 3.437 & 0.03720 & 2.124 & 0.00997 \\
\hline 7.526 & 0.41935 & 5.017 & 0.11619 & 3.391 & 0.03572 & 2.076 & 0.00939 \\
\hline 7.421 & 0.40081 & 4.942 & 0.11110 & 3.344 & 0.03437 & 2.031 & 0.00890 \\
\hline 7.317 & 0.38266 & 4.873 & 0.10638 & 3.299 & 0.03304 & 1.988 & 0.00844 \\
\hline 7.216 & 0.36586 & 4.807 & 0.10218 & 3.254 & 0.03165 & 1.943 & 0.00799 \\
\hline 7.116 & 0.34957 & 4.739 & 0.09795 & 3.210 & 0.03026 & 1.897 & 0.00754 \\
\hline 7.015 & 0.33380 & 4.676 & 0.09394 & 3.167 & 0.02901 & 1.854 & 0.00713 \\
\hline 6.918 & 0.31887 & 4.608 & 0.08983 & 3.125 & 0.02783 & 1.822 & 0.00685 \\
\hline 6.821 & 0.30430 & 4.545 & 0.08600 & 3.083 & 0.02673 & & \\
\hline
\end{tabular}

linear thermal expansion is anisotropic and varies more along the $c$ axis. This can be explained by the fact that $\mathrm{NaO} 6$ units are made of weak $\mathrm{Na}-\mathrm{O}$ bonds and are linearly connected along the $c$ axis as shown in Fig. 1. As often observed, thermal expansion varies inversely with the bond strength.

\section{Heat capacity}

The low-temperature heat capacity measurements data on $\mathrm{NaUO}_{2} \mathrm{BO}_{3}$ are presented in Table 2.

The heat capacity data have been fitted to a series of overlapping polynomials, and we derive for the $C_{\mathrm{p}}(298.15 \mathrm{~K})=(143.2 \pm 2.9) \mathrm{J} \mathrm{K}^{-1} \mathrm{~mol}^{-1}, S^{\circ}(298.15 \mathrm{~K})$ $=(174.9 \pm 3.5) \quad \mathrm{J} \cdot \mathrm{K}^{-1} \cdot \mathrm{mol}^{-1}, \quad$ and $\quad\left\{H^{\circ}(298.15 \mathrm{~K})-\right.$ $\left.H^{\circ}(0 \mathrm{~K})\right\}=(26.37 \pm 0.53) \mathrm{kJ} \mathrm{mol}^{-1}$. The errors were 
Fig. 3 a IR and Raman spectra of $\mathrm{NaUO}_{2} \mathrm{BO}_{3}$ at room temperature; $\mathbf{b}$ series of Raman spectra as a function of temperature in the range 6 to $290 \mathrm{~K}$. The inset shows the full sizes of the most intense peak at $788 \mathrm{~cm}^{-1}$. No significant change in position is observed. The slight asymmetry at lower wavenumbers is increasing with increasing temperature
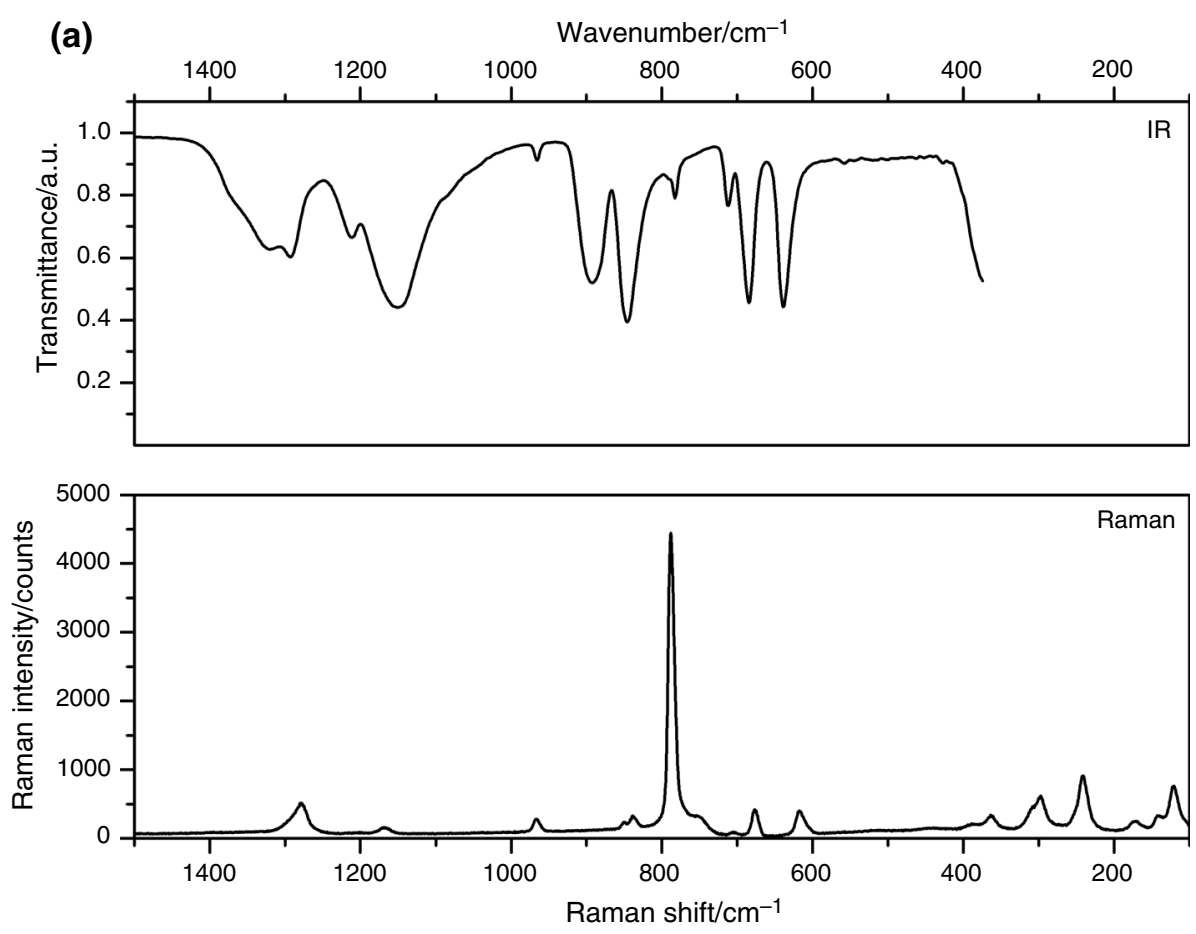

(b)

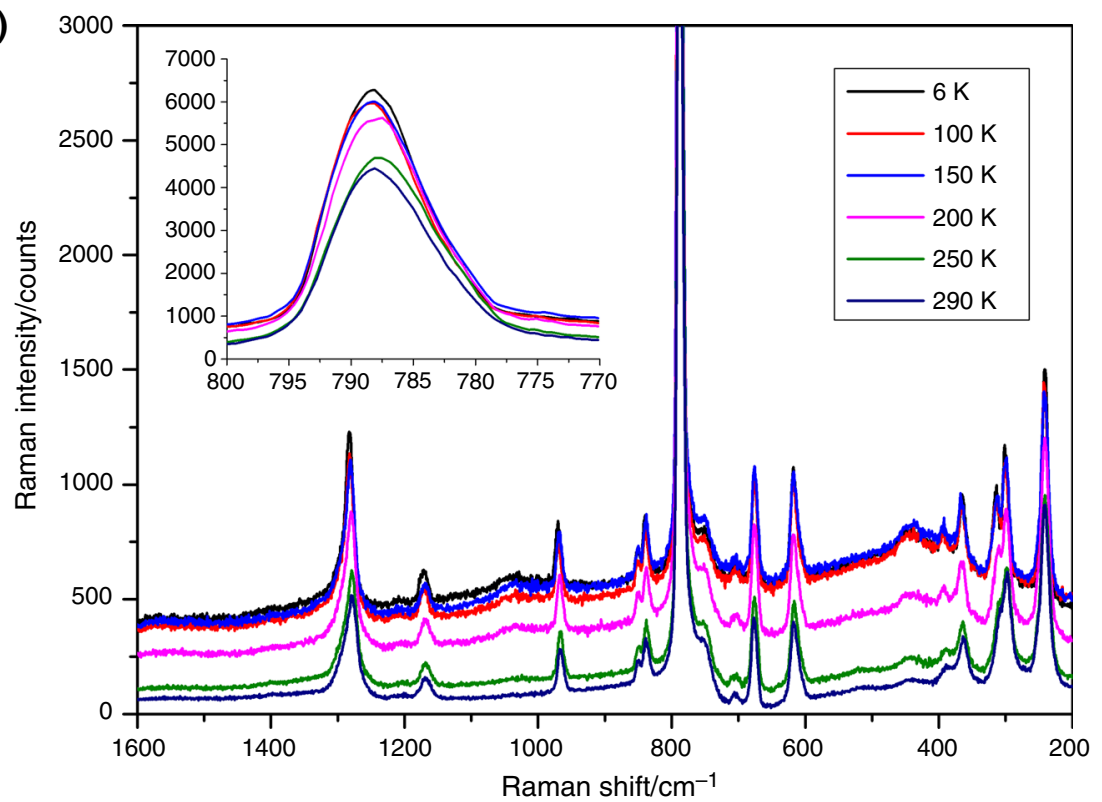

estimated from the accuracy of the equipment, which is in the order of $2 \%$.

The low-temperature heat capacity measurements indicate an anomalous change in the slope of the curve at about $175 \mathrm{~K}$. Our results agree satisfactory with the measurements reported by Karyakin et al. [6] (supplementary material S2), including the anomaly that was not identified as such by them. It should be noted that our measurements were performed from room temperature downwards, whereas Karyakin et al. measured from low temperature upwards. This phenomenon was further analysed by performing X-ray diffraction and IR, respectively, and Raman spectroscopic measurements in the low-temperature range. Figure $3 \mathrm{a}, \mathrm{b}$ summarises the IR and Raman spectra at room temperature and the temperature-dependent Raman spectra in the range from 6 to $290 \mathrm{~K}$. The IR spectrum corresponded to earlier investigations by Hoekstra [4]. To our knowledge, there is no Raman spectrum of sodium uranyl borate reported in the literature. Anyhow, the temperaturedependent series showed no significant differences in the 
Table 3 Enthalpy increment $H^{\circ}\left(T_{\mathrm{m}}\right)-H^{\circ}\left(T_{\mathrm{a}}\right)$ of $\mathrm{NaUO}_{2} \mathrm{BO}_{3}\left(T_{\mathrm{m}}-\right.$ measurement temperature, $T_{\mathrm{a}}$-ambient temperature)

\begin{tabular}{lll}
\hline$T_{\mathrm{m}} / \mathrm{K}$ & $T_{\mathrm{a}} / \mathrm{K}$ & $H^{\circ}\left(T_{\mathrm{m}}\right)-H^{\circ}\left(T_{\mathrm{a}}\right) / \mathrm{kJ} \mathrm{mol}$ \\
\hline 482.5 & 294.2 & $29.94 \pm 0.88$ \\
533.9 & 294.2 & $38.34 \pm 0.49$ \\
585.8 & 294.2 & $50.38 \pm 0.43$ \\
636.5 & 294.2 & $58.76 \pm 0.63$ \\
687.5 & 294.2 & $65,11 \pm 1.00$ \\
738.0 & 294.2 & $76.30 \pm 1.34$ \\
788.5 & 294.2 & $84.90 \pm 2.57$ \\
838.7 & 294.2 & $97.35 \pm 0.52$ \\
889.0 & 294.2 & $105.22 \pm 3.71$ \\
938.7 & 294.2 & $115.29 \pm 3.75$ \\
989.0 & 294.2 & $121.12 \pm 2.59$ \\
1039.3 & 294.2 & $128.59 \pm 3.89$ \\
1089.6 & 294.2 & $143.51 \pm 9.45$ \\
1139.7 & 294.2 & $154.08 \pm 7.32$ \\
1190.5 & 294.2 & $165.87 \pm 2.95$
\end{tabular}

The error indicated is the standard deviation of the average value from several sample drops

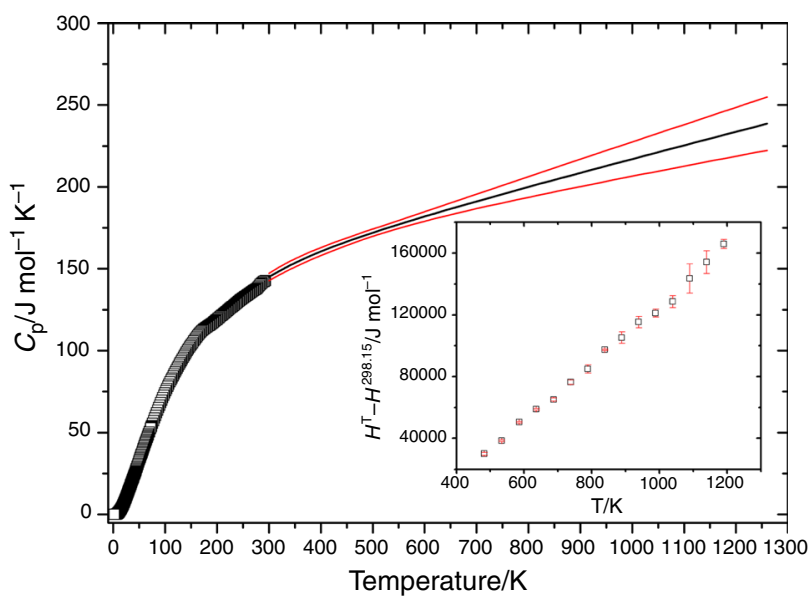

Fig. 4 Heat capacity $\left(\mathrm{J} \mathrm{K}^{-1} \mathrm{~mol}^{-1}\right)$ of $\mathrm{NaUO}_{2} \mathrm{BO}_{3}$ as a function of temperature, (square) low-temperature data, (solid black line) the heat capacity obtained from the drop calorimeter, (solid red line) confidence band. Inset: the measured enthalpy increments with their standard deviations

spectra with temperature variation. This is in agreement with the X-ray diffraction data; neither of them showed any clear indication of a structural transformation. We therefore conclude that the origin of the anomaly in the heat capacity must be of a diffuse nature, which could be related to a slow and slight structural reordering of oxyanionic units, which cannot be detected by X-ray diffraction or Raman spectroscopy.

The enthalpy increment data derived for $\mathrm{NaUO}_{2} \mathrm{BO}_{3}$ are shown in Table 3 and in Fig. 4. All measured enthalpy
Table 4 Thermal diffusivity and thermal conductivity of $\mathrm{NaUO}_{2} \mathrm{BO}_{3}$

\begin{tabular}{|c|c|c|}
\hline$T / \mathrm{K}$ & $\begin{array}{l}\text { Thermal diffusivity } \\
10^{-7} \mathrm{~m}^{2} \mathrm{~s}^{-1}\end{array}$ & 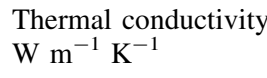 \\
\hline 513.6 & 2.376 & 0.641 \\
\hline 513.6 & 2.385 & 0.643 \\
\hline 513.8 & 2.387 & 0.644 \\
\hline 513.9 & 2.384 & 0.643 \\
\hline 568.1 & 2.297 & 0.631 \\
\hline 569.9 & 2.304 & 0.633 \\
\hline 571.1 & 2.289 & 0.630 \\
\hline 615.3 & 2.250 & 0.626 \\
\hline 616.1 & 2.248 & 0.626 \\
\hline 616.3 & 2.250 & 0.626 \\
\hline 690.0 & 2.176 & 0.614 \\
\hline 692.2 & 2.175 & 0.615 \\
\hline 693.6 & 2.169 & 0.613 \\
\hline 769.0 & 2.143 & 0.612 \\
\hline 769.3 & 2.146 & 0.613 \\
\hline 769.1 & 2.152 & 0.615 \\
\hline 826.5 & 2.131 & 0.613 \\
\hline 827.8 & 2.135 & 0.615 \\
\hline 829.0 & 2.142 & 0.616 \\
\hline 893.5 & 2.186 & 0.633 \\
\hline 894.9 & 2.194 & 0.636 \\
\hline 895.1 & 2.198 & 0.637 \\
\hline 959.3 & 2.253 & 0.655 \\
\hline 960.4 & 2.261 & 0.657 \\
\hline 960.9 & 2.271 & 0.660 \\
\hline 1018.9 & 2.234 & 0.652 \\
\hline 1022.0 & 2.252 & 0.658 \\
\hline 1023.1 & 2.241 & 0.654 \\
\hline 1017.4 & 2.254 & 0.658 \\
\hline 1017.8 & 2.257 & 0.659 \\
\hline 1077.2 & 2.190 & 0.642 \\
\hline 1077.3 & 2.194 & 0.643 \\
\hline 1076.9 & 2.196 & 0.643 \\
\hline 1130.0 & 2.127 & 0.625 \\
\hline 1130.0 & 2.116 & 0.622 \\
\hline 1130.0 & 2.147 & 0.631 \\
\hline
\end{tabular}

increment data were fitted using a combined linear regression together with the room temperature heat capacity data obtained from the PPMS measurements performed as part of this study. A Maier-Kelly-type second-order polynomial equation was used, similar to our previous studies for alkaline and alkaline-earths uranates [14, 15]. The following heat capacity equations were obtained: 

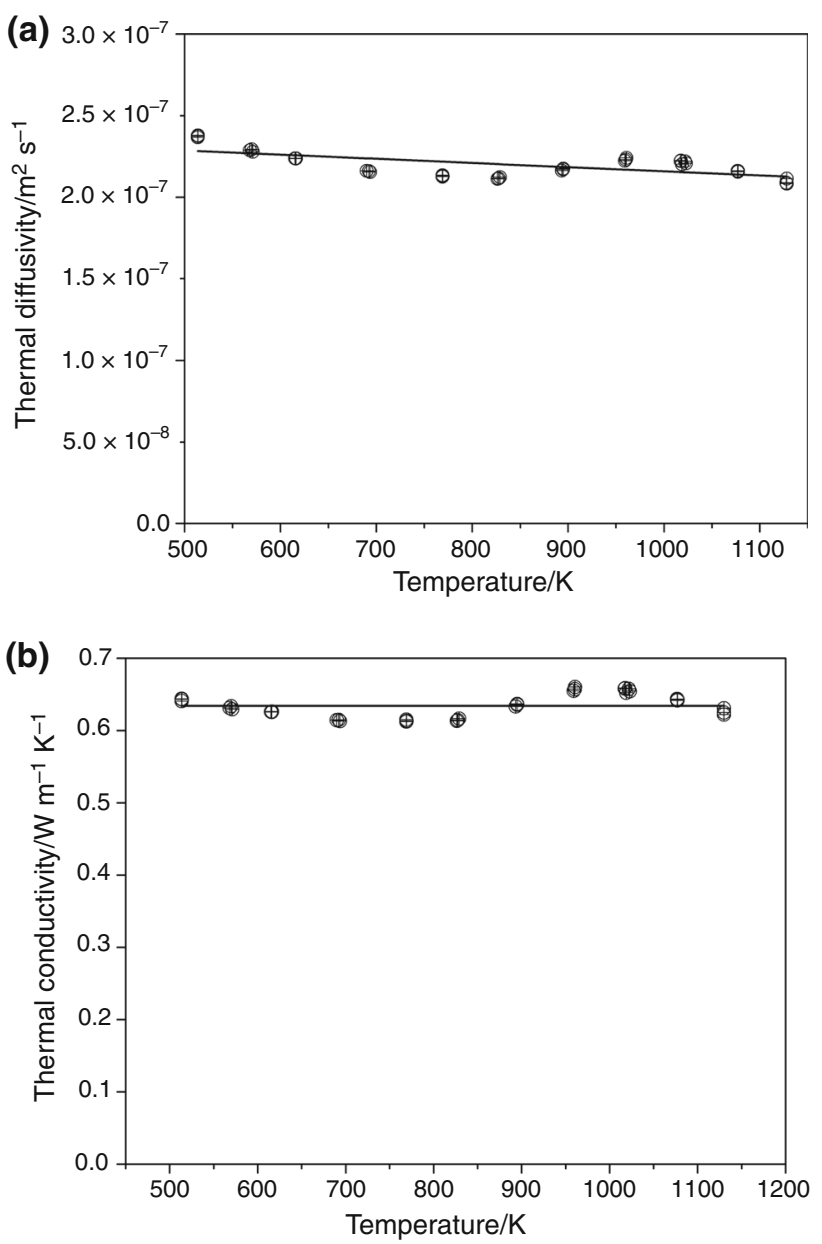

Fig. 5 Thermal diffusivity (a) and conductivity (b) of $\mathrm{NaUO}_{2} \mathrm{BO}_{3}$

$$
\begin{aligned}
C_{\mathrm{p}, \mathrm{m}}^{\mathrm{o}} / \mathrm{J} \mathrm{K}^{-1} \mathrm{~mol}^{-1}= & (188.3 \pm 27.8)+\left(11.20 \times 10^{-3}\right. \\
& \left. \pm 3.97 \times 10^{-3}\right)(T / K)-\left(4.308 \times 10^{6}\right. \\
& \left. \pm 1.431 \times 10^{6}\right)(T / K)^{-2} .
\end{aligned}
$$

\section{Thermal diffusivity and conductivity}

The results of the thermal diffusivity measurements are listed in Table 4, and are shown in Fig. 5a. The relative uncertainty on the thermal diffusivity measurements is of $5 \%$, mainly due to sample thickness variations. The sample thickness change due to thermal dilatation was corrected using the thermal expansion data obtained in this work. The results show very moderate temperature dependence and can be described by the following equation:

$\alpha /\left(\mathrm{m}^{2} \mathrm{~s}^{-1}\right)=2.398 \times 10^{-7}-2.093 \times 10^{-11}(T / K)$.

The thermal conductivity of the compound was calculated from the measured thermal diffusivity, heat capacity, and density using the formula: $\lambda=\rho \times \alpha \times C_{\mathrm{p}}$.

The density of the samples, measured by the Archimedes technique at ambient temperature, was of $5.37 \mathrm{~g} \mathrm{~cm}^{-3}$ (98\% of the theoretical density, with $\mathrm{TD}=5.50 \mathrm{~g} \mathrm{~cm}^{-3}$ ). The temperature dependence of the density was calculated using the thermal dilatation data obtained in this work.

The obtained sample thermal conductivity (Fig. 5b) showed no significant temperature dependence and was therefore considered to be temperature independent, with a value of $\lambda /\left(\mathrm{W} \mathrm{m}^{1} \mathrm{~K}^{-1}\right)=0.634$, which is very low for a ceramic material $[16,17]$.

The relative uncertainty on the calculated thermal conductivity is estimated to be of $10 \%$, resulting from the sum of the uncertainties on the thermal diffusivity (5\%), specific heat $(3 \%)$, and density (2\%).

\section{Conclusions}

- The linear thermal expansion of $\mathrm{NaUO}_{2} \mathrm{BO}_{3}$ is very anisotropic along all the crystallographic axes.

- The anomalous change in the curve of the lowtemperature heat capacity at about $175 \mathrm{~K}$ found by Karyakin et al. [6] was reproduced, indicating that it is a genuine effect.

- The thermal conductivity of $\mathrm{NaUO}_{2} \mathrm{BO}_{3}$ was found to be very low for a ceramic material.

Acknowledgements The authors acknowledge Daniel Bouexière, Co Boshoven, Herwin Hein, Michael Holzhäuser, Davide Robba, and Marc Sierig, for technical support.

Open Access This article is distributed under the terms of the Creative Commons Attribution 4.0 International License (http://crea tivecommons.org/licenses/by/4.0/), which permits unrestricted use, distribution, and reproduction in any medium, provided you give appropriate credit to the original author(s) and the source, provide a link to the Creative Commons license, and indicate if changes were made.

\section{References}

1. Wang S, Alekseev EV, Ling J, Liu G, Depmeyer W, AlbrechtSchmitt TE. Polarity and chirality in uranyl borates: insights into understanding the vitrification of nuclear waste and the development of nonlinear optical materials. Chem Mater. 2010;22:2155-63.

2. Wang S, Alekseev EV, Diwu J, Miller HM, Oliver AG, Liu G, Depmeyer W, Albrecht-Schmitt TE. Functionalization of borate networks by the incorporation of fluoride: syntheses, crystal structures, and nonlinear optical properties of novel actinide fluoroborates. Chem Mater. 2011;23:2931-9.

3. Silver MA, Albrecht-Schmitt TE. Evaluation of f-elements borate chemistry. Coord Chem Rev. 2016;323:36-51. 
4. Hoekstra HR. Uranyl metaborate and sodium uranyl borate. In: Fields P, et al., editors. Lanthanide and actinide chemistry, advances in chemistry. Washington, DC: ACS; 1967. p. 320-30.

5. Gasperin M. Synthese et structure du borouranate de sodium, $\mathrm{NaBUO}_{5}$. Acta Cryst. 1988;C44:415.

6. Karyakin NV, Chernorukov NG, Knyazev AV, Feoktistova OV, Alimzhanov MI, Feoktistova MA. The thermodynamic properties of sodium uranoborate. Russ J Phys Chem. 2002;76:347-50.

7. Chernorukov NG, Knyazev AV, Kortikova OV, Sergacheva IV. Thermochemistry of alkali metal uranoborates and their crystal hydrates. Radiochemistry. 2003;45:122-6.

8. Rodriguez-Carjaval J. Recent advances in magnetic structure determination by neutron powder diffraction. Phys B. 1993;192:55-69.

9. Lashley JC, Hundley MF, Migliori A, Sarrao JL, Pagliuso PG, Tarling TW, Jaime M, Cooley JC, Hults WL, Morales L, Thoma DJ, Smith JL, Boerio-Goates J, Woodfield BF, Stewart GR, Fisher RA, Phillips NE. Critical examination of heat capacity measurements made on quantum design physical property measurement system. Cryogenics. 2003;43:369-78.

10. Javorský P, Wastin F, Colineau E, Rebizant J, Boulet P, Stewart G. Low-temperature heat capacity measurements on encapsulated transuranium samples. J Nucl Mater. 2005;344:50-5.
11. Popa K, Shvareva T, Mazeina L, Colineau E, Wastin F, Konings RJM, Navrotsky A. Thermodynamic properties of $\mathrm{CaTh}\left(\mathrm{PO}_{4}\right)_{2}$ synthetic cheralite. Am Mineral. 2008;93:1356-62.

12. Beneš O, Popa K, Reuscher V, Zappia A, Staicu D, Konings RJM. High-temperature heat capacity of $\mathrm{PuPO}_{4}$ monazite-analogue. J Nucl Mater. 2011;418:182-5.

13. Sheindlin M, Halton D, Musella M, Ronchi C. Advances in the use of laser-flash techniques for thermal diffusivity measurements. Rev Scient Instr. 1998;69:1426-36.

14. Popa K, Wastin F, Colineau E, Konings RJM. The heat capacity of $\mathrm{BaUO}_{4}$. J Chem Thermodynamics. 2007;39:104-7.

15. Konings RJM, Popa K, Colineau E, Wastin F. The low-temperature heat capacity of $\mathrm{CaUO}_{4}$ and $\mathrm{SrUO}_{4}$. J Chem Thermodynamics. 2008;40:220-4.

16. Pujula M, Sánchez-Rodríguez D, Lopez-Olmedo JP, Farjas J, Poura P. Measuring thermal conductivity of powders with differential scanning calorimetry. A simplified method. J Therm Anal Calorim. 2016;125:571-7.

17. Almeida TF, Leite FHG, Faira RT Jr, Holanda JNF. Thermal study of calcium silicate material synthesized with solid waste. J Therm Anal Calorim. 2017;128:1265-72. 